\title{
Knowledge sharing and organizational change: Practice interactions in Australian local government
}

\author{
Dean Leith \\ University of Technology Sydney, Australia \\ Hilary Yerbury \\ University of Technology Sydney, Australia
}

\begin{abstract}
The sharing of knowledge in organizations is deemed critical to achieving environmental and economic sustainability outcomes. This study applies a practice theoretical approach to investigating knowledge sharing in a team in local government created to break down the boundaries which have led to siloed practices. Findings indicate a range of activities, including influencing and resisting, and these differ from findings in other studies. Analysis of organizational discourses, physical arrangements and social spaces of organizations demonstrated the existence of two distinct practices: knowledge sharing and organizational change. Sharing knowledge of the organization and its ways of working were found to be as important as sharing subject knowledge and expertise.
\end{abstract}

\section{Keywords}

Knowledge sharing, organizational change, phenomenology, practice architectures, practice theory

Over the last several decades, Australian governments at the local, state and federal levels have sought to address increasing community demands for greater environmental and economic sustainability. The sharing of knowledge within and between organizations is critical to the success of these efforts as traditional organizational structures are questioned and new structures, processes and practices are introduced to achieve greater sustainability outcomes (Gillen, 2004; Tomaney, 2010; Untaru, 2002). Research in the knowledge management and organizational studies literature reflects this strong interaction between knowledge sharing and organizational change. Knowledge-sharing initiatives such as projects to implement knowledge-sharing systems and practices often require review of traditional structures and associated change management efforts. Conversely, organizational change management projects often rely on collaboration, co-operation and knowledge sharing across and between organizations to be successful. Many research studies have taken an information behaviour' approach (Frohman, 1992; Ingwersen, 1992; Wilson 1996) in which information needs and seeking tend to be given an external, objective and concrete sense: an existence separate from the acting, perceiving being (Hepworth et al., 2014). While these studies are valuable in that they provide a wealth of data on information behaviour and the factors that may impact on it, more recent practice-based approaches are gaining ground (Pilerot et al., 2017). Practice-based approaches view information practices as contextual, social, embodied and material (Reckwitz, 2017) and they approach 'reality' as mediated, subjective and in a constant state of flux (Hepworth et al., 2014).

This study explores interactions between knowledge sharing and organizational change in an Australian local government organization, called here the Avenir Council. It investigates the activities that constitute both knowledge sharing and organizational change in this context; to uncover interactions between them; and to identify the impact of the wider organizational arrangements on both knowledge sharing and organizational change. The study applies a practice theoretical approach arising from the work of Schatzki $(2002,2012)$ and Kemmis $(2009,2014)$; an approach also explored in the library and information management field in studies of information sharing (Pilerot, 2013), knowledge sharing (Leith and Yerbury, 2015) and information literacy (Lloyd, 2012). This study demonstrates how this focus on what people actually do offers a more comprehensive and nuanced understanding of the dynamics of organizational knowledge sharing and change than previous approaches focusing only on information behaviour. 


\section{Review of the literature}

Park and Kim (2015), in a review of recent knowledge management research, suggest that the literature reflects a close association between knowledge sharing and organizational change and further, that human and structural components of knowledge sharing have a greater impact on organizational change than task or technology components. They conclude that organizations that seek to innovate and implement organizational change initiatives need to consider the people and structural aspects of knowledge sharing before engaging in change initiatives. In an earlier survey of knowledge management research, Patel et al. (2011) concluded that, while research reflected a strong association between knowledge sharing and organizational change, it had not fully engaged with the role of knowledge-sharing initiatives in organizational work processes and their relationship to engagement in organizational change.

\section{Practice approaches}

A practice theoretical approach is concerned with what people do in groups, such as work groups, that require some level of cooperation and social interaction. Practices are evidenced in what Schatzki (2012) refers to as doings and sayings. These doings and sayings [are] 'a point of departure for exploring the nets of activities and groupings of the practice at hand' (Nicolini and Monteiro, 2017: 111). Activities, another important term in the practice theoretical approach, are essentially what people do to fulfil their purposes and implement their projects (Schatzki, 2012: 15). In the context of an organization, the sayings of a practice may constitute the verbal exchanges between workers involved in a task in their workplace and include the ways they talk to others about what they do, while the doings are the physical actions they undertake to carry out a task or activity. Kemmis and Grootenboer (2008) add a third category, relatings: the ways in which people relate to one another and interact with the broader organizational and societal context.

In a practice theoretical study undertaken by Price (2009), in the context of an Australian local government organization, workers at various levels of the organization were found to exert a significant impact on organizational change efforts through sharing their knowledge and expertise with existing colleagues and others new to the organization. Through this process, workers were able to re-shape their jobs, highlight organizational tensions and create significant learning opportunities across the organization to bring about change (Price, 2009). Similarly, taking a practice theoretical approach, Kemmis (2009) stresses the importance of knowledge sharing in the evolution of professional practices in organizations. He suggests that changing practice goes beyond what the practitioners actually do and can transform the social relationships that constitute practice in an organization as well as the way these activities are understood.

What people do, these tasks and activities, are impacted by what Schatzki (2012) refers to as material arrangements, those factors such as people, artefacts, organisms or things present in the organizational context in which people work. Kemmis and Grootenboer (2008) extend Schatzki's concept of material arrangements, identifying three different kinds of arrangements that occur simultaneously in a site of practice and impact on or mediate practices, forming practice architectures. The theory of practice architectures provides an account of how practices shape and are shaped by the organizational arrangements within which they are enmeshed in a site (Mahon et al., 2017). Thus, practices are shaped and pre- figured by arrangements that go beyond the participants engaged in the practice (Kemmis and Grootenboer, 2008: 37). In the case of knowledge sharing in this study, the theory assists in considering how knowledge sharing may be shaped by the broader factors or arrangements of the organization and how the practice of knowledge sharing may, in turn, impact on these arrangements back in the wider setting.

Applied to this research investigation, the theory suggests that knowledge-sharing practice may extend beyond what each participant brings to the council context, such as their perspectives and abilities, to encompasses arrangements found in or brought to the council site; arrangements with which participants interact and without which knowledge sharing could not be realised (Mahon et al., 2017). These practice arrangements, the theory suggests, include cultural-discursive arrangements that interact with the sayings of a practice; material-economic arrangements that interact with the doings of a practice; and social-political arrangements that interact with the relatings of a practice. The theory of practice architectures suggests that practices, such as knowledge sharing, are always enmeshed in these 'three dimensions of inter-subjectivity' (Kemmis, 2014: 23) and, further, that cultural-discursive arrangements are realised in the semantic space, material eco-nomic arrangements in physical space-time and social political arrangements in the social space (Kemmis., 2014) of 
each organizational context. Each of these three types of arrangements mediates or shapes a particular practice, such that each practice has its own site-specific practice architectures, which may make possible, prefigure, mediate or hold it in place (Schatzki, 2002: 44).

\section{Methodology}

This study takes a practice theoretical approach to investigating the nature of knowledge sharing and change in the context of an Australian local government (council) organization. More specifically, it seeks to investigate the phenomena of knowledge sharing and organizational change, including the activities constituting them in this context, and to explore interactions between them (Mahon et al., 2017). The theory of practice architectures is used to consider the ways in which organizational practices are affected by the wider organizational arrangements and are, in turn, mediated by them. Van Manen's phenomenology of practice (2014) approach was adapted as a methodological approach for the study. The phenomenology of practice is specifically oriented to the concerns of professional practices in professional fields as well as to the personal and social practices of everyday living (Van Manen, 2014).

The participants in this study were members of a collaborative, multi-disciplinary project team involved in an initiative coordinated by a local council in Australia concerned with intra-agency knowledge sharing. The project team had been created by council management to use their knowledge and expertise in projects concerning environmental sustainability and place-based planning and, in the process, transform the organization's policy, planning and work practices from a very traditional siloed structure and approach to a more collaborative workplace. The project team included members from disciplines as diverse as engineering, urban horticulture and community services and is identified here by the pseudonym Avenir Sustainability Project Team (ASPT). The research study was approved by the Human Research Ethics Committee of the University of Technology Sydney (UTS HREC 2014000191) and approval for the researcher to attend project team meetings and interview participants was granted by the ASPT project manager and endorsed by the organization's management. Data were collected between June 2014 and May 2015.

\section{Data collection}

Data collection was undertaken using three methods including meeting observations in which the researcher used a participant as observer stance (Kawulich, 2005) combined with sound recording of project team meetings; semi-structured phenomenological interviews following van Manen's phenomenology of practice, and the identification and collection of organizational documents for thematic analysis, such as project plans, meeting agendas and minutes and web pages describing the project. Criteria used for document selection included relevance to the project; relevance to overall council priorities; and relevance to wider state government planning and priorities. In addition, the documents needed to be publicly available, such as through the organization's website, or able to be made available by the project convener in the context of the approval granted by the University's Human Research Ethics Committee. Data collection focused on the knowledge sharing of this work team, which had also been established to work towards organizational change in the organization.

One researcher attended, observed and recorded nine meetings of the Avenir Sustainability Project team all ranging between one and one-and-a-half hours' duration, some of which included visits to community locations where projects were being planned. This approach pro- vided the opportunity to undertake close observations of what people did as well as to reflect on proceedings and record detailed notes on the social, bodily, affective and material aspects of the meeting proceedings. Verbal and non-verbal communication used by team members was noted by the researcher as this 'participant as observer' technique and reflection unfolded.

The phenomenological interview seeks to explore and gather experiential narrative, material and stories or anecdotes that may serve to achieve a richer and deeper under- standing of human phenomena (Van Manen, 2014), such as knowledge sharing and organizational change. In other words, it is concerned with the sayings of team members. The focus of the interview was on a recent knowledge sharing experience - one where they shared their knowledge with others and other recent experiences related to the project where they experienced the council either encouraging knowledge sharing activity or, on the other hand, inhibiting knowledge sharing.

The same researcher conducted 16 semi-structured interviews with Avenir Sustainability Project Team 
mem- bers each ranging between one and one-and-a-half hours' duration. All meetings and interviews were recorded using a small, unobtrusive device and all recordings were transcribed verbatim. Researcher notes were collated and attached to the appropriate meeting documentation and interview transcripts. As required by the UTS Human Research Ethics Committee, all electronic and paper records were de-identified and coding was used in order for the researcher to retain each team member's contact details if clarification was necessary.

Avenir Council documents were identified and obtained with assistance from the project convener and reviewed by the researchers including project plans and proposals, meeting minutes and other project related documentation.

\section{Data analysis}

A thematic analysis of interview transcripts was under- taken using emergent coding in order to identify participant sayings. This analysis employed Van Manen's (2014) approach of including holistic, selective and detailed readings. The analysis focused on the team members' experience of the phenomenon of knowledge sharing, and the activities involved in undertaking knowledge sharing. This process was repeated in order to explore the team members' experience of organizational change. The impact of the organizational site on knowledge sharing was also considered and how it affected, or mediated, knowledge sharing in context.

Emergent coding was also used for a thematic analysis of project meeting transcripts in order to identify participant doings and sayings. This analysis was supplemented by review of associated researcher notes in a similar manner to interviews as well as the researcher writing thematic drafts of each meeting. Van Manen (2014: 337) describes this technique as phenomenological reduction which is a thematic summary seeking to identify the heart or essence of the phenomena under investigation. In this way data from the team members' experiences of knowledge sharing and organizational change are supplemented with that of the researcher's. As the researcher was present at all project meetings and engaged in close observation, he witnessed activities as they unfolded between team members. A further analysis used a priori coding based on the theory of practice architectures (Mahon et al., 2017), matching the instances of sayings and doings against the three categories of the organization's semantic space, material space and social space.

Similarly, a priori coding was used for the analysis of organizational documents adapted from the three sets of practice arrangements identified in the theory of practice architectures, that is, cultural-discursive arrangements that interact with the sayings of a practice; material-economic arrangements that interact with the doings of a practice; and social-political arrangements that interact with the relatings of a practice (Mahon et al., 2017). This analysis focused on identifying the broader organizational factors impacting on knowledge-sharing and organizational change practices.

\section{Findings}

The initial thematic analysis found that knowledge-sharing practice by members of the team encompassed a range of activities including engaging, presenting, administering, supporting, resisting, influencing and problem solving. In a second analysis of organizational change practice, four activities were found to be common to both knowledge sharing and organizational change practices: engaging, presenting, influencing and resisting. These common activities, defined as the actions, doings and sayings that people carry out to meet their objectives (Schatzki, 2012), are the focus of this paper.

Engaging involved team members communicating and relating directly with each other in a variety of ways such as close one-on-one conversations to enthusiastically contributing to meeting activities and asking questions of speakers during presentations. Presenting, as an activity, involved team members conveying their knowledge via a prepared or impromptu presentation to an audience of two or more colleagues. Influencing involved exerting a compelling force on, or producing an impact on, the actions, behaviour or opinions of colleagues or others, while, resisting involved withstanding, arguing against or attempting to prevent the influence or actions of colleagues or others. At one level, it was unsurprising that these activities were identified as they are found in many studies of knowledge sharing in organizational contexts.

The use of the analytical frame of the theory of practice architectures, however, sheds light on nuances in the way these activities were used within the team. The analysis of discussions in the meetings provided evidence of the two sets of practices identified above. Each of the four activities identified was part of both practices. The analysis using practice architectures allows for a deeper understanding of knowledge sharing 
in organizations, the ways that people taking part in organizational change initiatives act and the significance of the context within which the members of a work team engage.

To explore the nuances and relationships between knowledge sharing and organizational change, data on all four activities: engaging, presenting, influencing and resisting will be presented. As engaging and presenting were viewed as normative activities of knowledge sharing, and well represented in previous literature, they are presented with single examples. Influencing and resisting will be analysed and presented in more detail, as they were found to offer greater insight into the interactions between the practices of knowledge sharing and organizational change in this study.

\section{Engaging and presenting}

Examples of engaging in knowledge sharing practice occurred commonly at team meetings and also during site visits as described by Gemma in the following example:

The site visits are an absolute eye opener and made us understand a lot more about each other's point of view. We all learned more about each other's jargon and - it's become much more human and friendly - and [we realised] even planting a tree is a complex thing - it's not simple and now we understand that...

Engaging as an activity in the practice of organizational change was seen as central to the team's role in the organization, as described by the project convener, Flick:

It's the five areas that are outside of our team, like finance, governance, IT, children's services and the library teams. We probably haven't made as much of an impact on those teams yet ... as they don't have representatives on our project.

Here Flick is acknowledging her team's successful engaging activity in organizational areas from which they have drawn team members, but that organizational change has been less successful in the areas less engaged in the project.

Presenting activities were varied, from the delivery of a pre-prepared formal presentation using technology such as computers and presentation software, to team members reporting back to the larger group on a small group discussion or casually reporting as part of a meeting agenda item or handing out or referring to documents and artefacts. The following example, taken from the observer's notes is typical of presenting as part of knowledge sharing practice:

Colin remained seated, but addressed the group for the first agenda item, entitled 'New project developments'. Looking around at participants, he began, 'Usually I am at the end product of things and I have been allowed to be at the front end ... to be part of that creative and collaborative process. The project that was really good was Smith Street ...' Many participants, including the invited managers nodded and grinned as Colin spoke.

Presenting as a component of organizational change practice, is illustrated by the project convener, Flick, as she described the content of a presentation she gave to her immediate team members including how she focused on Abby, a team member for whom change management was particularly difficult:

Yes, Abby does have a big role, so I directed a lot of the presentation to her. There is a great number of things in Finance that need to change so I needed to make sure that she is aware of what we are doing and providing input and owning it as much as everybody else.

It is not surprising to find such strong and frequent examples of engaging and presenting in both knowledge sharing and organizational change. Influencing and resisting are also activities that the literature acknowledges are to be expected in knowledge-sharing projects aimed at organizational change. The analysis in this study showed that both influencing and resisting were very significant activities for this team, with examples emerging from the practices of knowledge sharing and organizational change and mediated by each of the three 'spaces' identified in the theory of practice architectures.

\section{Influencing, resisting and the theory of practice architectures}


Using the analytical framework of the theory of practice architectures (Kemmis and Grootenboer, 2008; Kemmis and Mutton, 2012), Figure 1 shows how influencing aimed at colleagues, managers and the community was impacted by the broader semantic, physical and social spaces of knowledge sharing, as well as from organizational change practice. The following examples show how knowledge- sharing practice and organizational change practice were evident in the doings and sayings of the team.

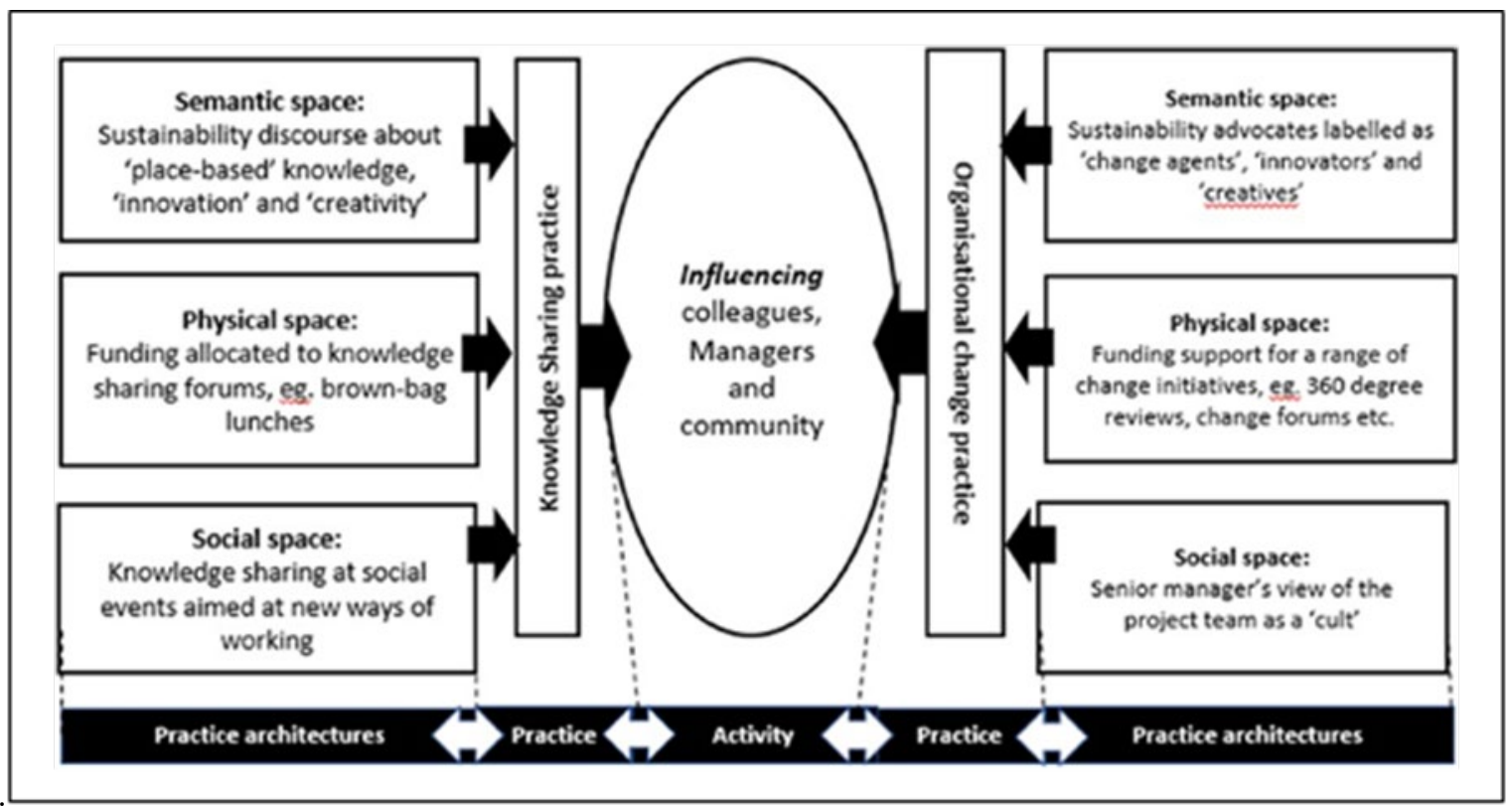

Figure 1. Impact of practice architectures on practices and influencing activity

An analysis of Avenir Council documents showed that, in the semantic space, many managers and staff spoke about 'place-based knowledge' and the need to recognize 'innovation' and 'creativity' in the Council. Similarly, from the physical space, documents showed that managers funded knowledge sharing at 'brown bag lunches' and, in the social space, team members engaged with new ways of working. Participant Gemma describes a social occasion where she sought to influence colleagues about including water management as an integral part of their planning, not as an add-on activity:

I saw Johnny and Wendy at lunch and they raised the water management plan and I said: 'Remember water services and its design is not add-on infrastructure - we have got to be moving to integrating all that - we are supposed to be modeling the new way of doing it'. They were silent - but later on, at the next meeting, they were making great suggestions about the plan, and I knew I'd had an impact on their thinking ...

The semantic, physical and social spaces also impacted on influencing activities from the perspective of organizational change practice. In the semantic space, sustainability advocates were labelled as change agents as reported by Hal:

I think that, as a team, we have driven culture change here and people refer to us as 'the change agents'.

In the physical space, organizational reports referred to funding for programs of which team members were a part and supporting a range of change initiatives to assist the organization's transition to new ways of working which included 360-degree reviews for managers and supervisors as well as creativity and change management workshops. From the social space, participant Nick had discussions with his manager who recently attended and observed an ASPT meeting. The researcher recorded the following notes from Nick's report back to the team about the feed- back his manager had given him after the meeting:

Nick was asked what feedback his manager had from his six- monthly team observation, and he was quite reticent to respond and replied, 'Um, I am not sure I can repeat it', which sparked much interest and some laughter across the group. Some people raised their eyebrows and fixed their gaze on Nick. After further coaxing by others, Nick replied, 'He said that he felt a bit like he was in a cult!' The whole group erupted into gales of laughter with several members 
looking shocked, wide-eyed and open-mouthed.

This exchange revealed how the team had become very close, and almost evangelical, in their promotion of sustainability across the Council, and this had cemented close social, as well as professional, bonds between team members.

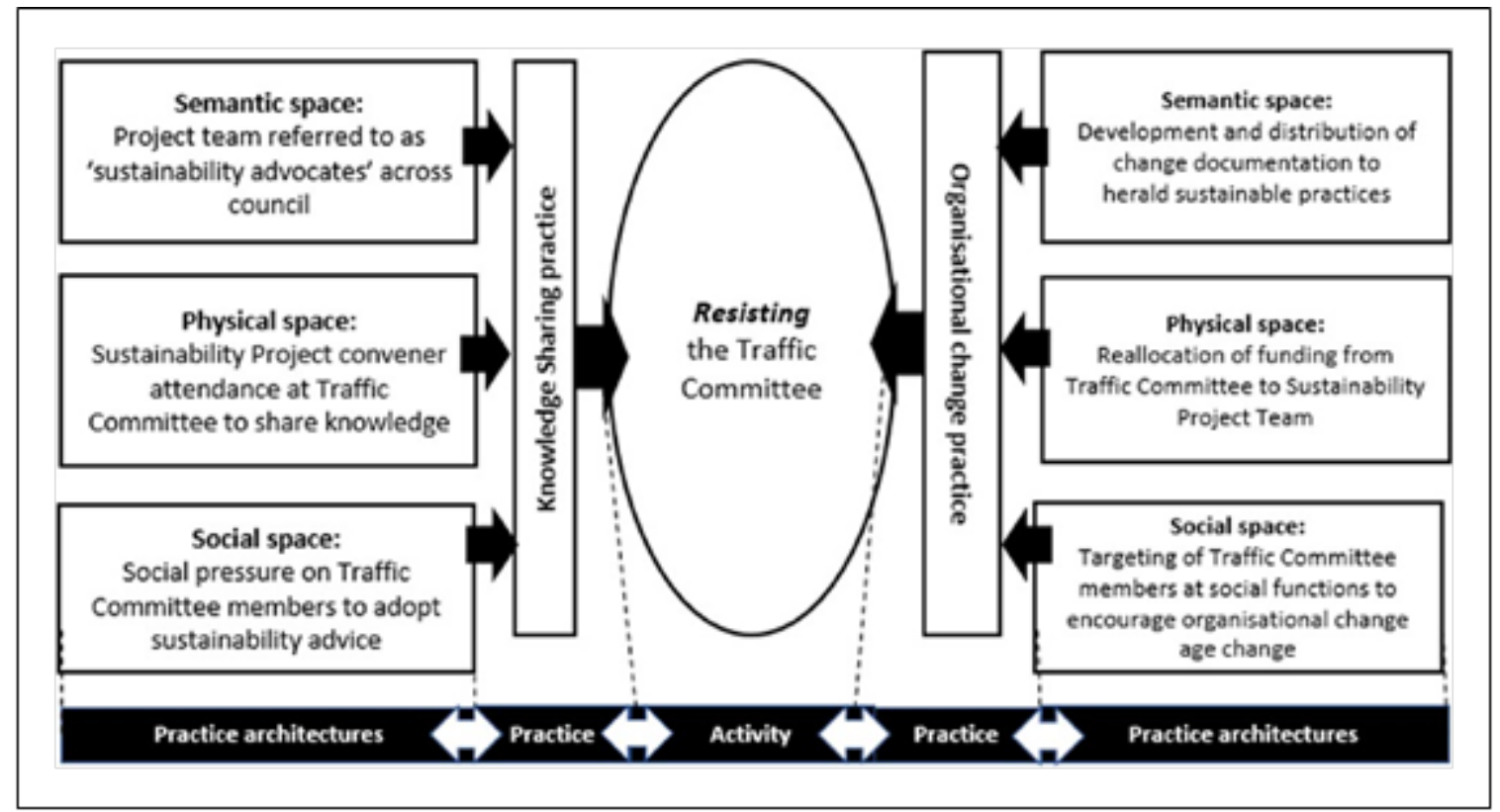

Figure 2. Impact of practice architectures on practices and resisting activity.

Again, using the analytical frame of the theory of practice architectures (Kemmis and Grootenboer, 2008; Kemmis and Mutton, 2012), Figure 2 shows how resisting aimed at the Traffic Committee, was impacted by the broader semantic, physical and social spaces of knowledge sharing, as well as from organizational change practice. The examples that follow show how knowledge-sharing practice and organizational change practice were evident in the doings and sayings of the team.

Emerging from the semantic space of knowledge-sharing practice, team members were referred to as 'sustainability advocates' across the entire Council and became authorities worthy of representing the organization at external forums. Team members used their knowledge and skills to argue strongly against traditional restrictions such as those imposed by traffic engineers. From the physical space, the project convener was supported to attend Traffic Committee meetings to share her knowledge about sustainability in order to resist the traditional approaches of the Committee. This, combined with resistance from the social space, sought to lift restrictions and ensure more flexibility around adherence to codes imposed by Traffic Committee members. The following exchange reveals the team's reactions to the restrictions of the Traffic Committee:

Flick: Yes both Jill and I have been trying to attend all the Traffic Committee meetings.

Gemma: Excellent - yes - that's the target isn't it - the Traffic Committee!

Jack: We probably all need to go to the Traffic Committee, one by one, and plead our case ...

The semantic, physical and social spaces also impacted on resisting activities from the perspective of organizational change practice. In the semantic space, Avenir Council developed a range of documentation aimed at challenging traditional planning restrictions, often advocated by the Traffic Committee, and heralding more sustainable practices. From the physical space, it became clear that some new programs were funded through the redirection of funding away from traditional traffic engineering as indicated in Council meeting 
minutes and associated documentation. In the social space, project team members openly targeted specific Traffic Committee members at social functions to deliver sustainability messages in order to resist traffic codes and impacts to their projects. Team member, Oliver, also a traffic engineer, described how he approached a Traffic Committee member at a social occasion to explain:

If the parking numbers are an issue then you could reclaim a lot of that angle parking from the verge gardens, but, if that changes the character of the street to something that is unacceptable to the Sustainability Project, then that's just not an option!

This example indicates the strength of the resistance of some of the team members which was exercised even in the context of a social occasion.

\section{Discussion}

The study found that several practices co-exist. The sayings, doings and relatings of the team clearly demonstrated their knowledge sharing and organizational change practices. Practices of sustainability and environmental management were also apparent but are not considered further here. Knowledge sharing and these other practices shared certain common constituent activities in the context of the Avenir Council, thereby interacting and becoming 'enmeshed' together (Mahon et al., 2017). In the case of knowledge sharing and organizational change, these two practices inter- acted together through the common activities of engaging, presenting, resisting and influencing. Engaging and presenting activities are often described in the knowledge management and organizational studies literature as key activities in both knowledge sharing and organizational change. The timeliness, context, techniques and creativity aspects of engaging and presenting in knowledge sharing are highlighted as they are in other studies (Afrazeh and Zarinozv, 2010; Cudney et al., 2015; Mayfield, 2010; Navimipour and Charband, 2016). Similarly, improving the dynamics of engagement and presentation during organizational change programs are also a significant focus in the literature (cf. Atkinson, 2011; Baesi and Benjinaru, 2014; Feldman and Pentland, 2003).

The study reinforces a view of information practices as contextual, social, embodied and material (Reckwitz, 2017). The characteristic features and arrangements of the Avenir Council, as reflected in organizational documents and the emerging semantic, physical and social spaces, were found to mediate the information practices of team members, such as knowledge sharing, in ways particular to this council site. Information practices were found to be enmeshed in the social realm as illustrated by the intense and productive interactions between team members. Embodiment and materiality were also critical dimensions of knowledge sharing practice at the Avenir Council through team members' demonstration of physical responses and interactions during meetings. As well as bodily engagement with material arrangements such as projectors, computers, chairs and tables people interacted with organizational documents such as agendas, minutes, plans and reports. The findings also reinforce a view of practices as mediated, subjective and in a constant state of flux (Hepworth et al., 2014).

Previous practice theoretical research by Price (2009) was also reinforced by this study in that despite their middle-management status, team members were, like Price's participants, found to exert a significant impact on organizational change efforts through sharing their knowledge and expertise with colleagues in the organization. Through this process, workers were active in developing their job roles, highlighting organizational tensions through the activities of influencing and resisting and create learning opportunities and change across the organization. Kemmis's (2009) research findings were also reinforced by this study in that team members were responsible for transforming the social relationships that constitute practice in their organization as well as the way these activities are understood.

The practice theoretical approach used in the study enabled the activities of resisting and influencing to be seen in a different light from that of previous research. In the organizational change literature, influencing is seen as a form of persuasion undertaken by senior and middle managers, change agents, change managers and trainers through both the demonstration of positive change behaviours and through direct interaction with organizational staff (Battalina and Casiaro, 2012; Blake and Lloyd, 2008; Davis and Boulet, 2016; McCallum et al., 2008. As Price (2009) found, team members in this study were found to be very influential despite their relative position in the organization. Indeed, these team members became key 'change agents' and were recognized as such across all levels of the organization. The influence from their knowledge sharing was bottom 
up and sideways; not top down, as a range of previous studies have suggested. Knowledge-sharing influence was also a way of model- ling practices which are not only supported by senior management but in which team members themselves have a strong belief.

With respect to resisting, previous studies, especially organizational change studies, often focus on resisting as an activity that operates against change, that is, people are usually resisting the change itself (Georgalis et al., 2014; Lozano, 2012; McGuiness and Cronin, 2016; Pieterse et al., 2012). Organizational studies research also suggests that resistance often arises through lack of participant involvement and effective communication as well as managers' lack of influence across the organization (Battilana and Casciaro, 2013; Canning and Found, 2015). Resisting is seen as either active such as being openly critical, aggressive or violent and finding fault; as passive, such as not cooperating, procrastinating or with- holding information; (Canning and Found, 2015); as lack of trust arising from perceived injustice (Georgalis et al., 2015); as informational, emotional, behavioural or systemic (Lozano, 2012); or as unarticulated non-alignments of professional discourses (Pieterse et al., 2012). However, this study found that team members shared information in order to resist, that is, in order to combat 'the old ways' of working. In this study, team members were, in fact, resisting the opposition to change such as that represented by the traditional rules and regulations of the Traffic Committee. This was also linked to their belief in knowledge sharing and the need to find new ways of working in order to achieve sustainability in the environment.

In the context of the Avenir Sustainability Project, the two practices of knowledge sharing and organizational change were mediated by influences from the three spaces proposed in the theory of practice architectures (Mahon et al., 2017). In the case of both practices, various dis- courses and other influences from the semantic space mediated team members' sayings, and were, in turn, mediated by these sayings, facilitating a vocabulary of expertise, creativity and innovation. Likewise, the physical space-time impacted on team members' doings, by pro- viding resources to favour some practices over others, as well as to set up the conditions whereby particular team members may participate in certain meetings, in order to facilitate sharing and enact change. In addition, the social space impacted on the relatings of these practices by set- ting up particular social interactions, favouring some team members' views and not others. This mediated the way team members shared their expertise and how they related to each other and the rest of the organization and the com- munity, and impacted on broader contexts of organizational workings such as approaches to problem solving. The existence of influencing and resisting in both knowledge sharing and organizational change practices indicate the importance of these activities for the work of the team. The doings, sayings and relatings of the team recorded during their meetings can be understood beyond the con- text of the meetings themselves and interpreted in the wider context of the organization and of environmental management.

The use of the theory of practice architectures (Kemmis and Grootenboer, 2008), with its three dimensions of inter-subjectivity bundled together in semantic space, in physical space-time and in social space, has shown how the activities involved in knowledge sharing and organizational change are intertwined. The use of practice architectures has also shown how the discussions in team meetings and the knowledge that is shared there are linked into the policies and processes of the council as a whole. The relationship to the Traffic Committee and the activity of resisting can only be fully understood in the light of the approach and reputation of this committee as being guided by its 'codes' and 'rules'. In addition, this committee's work was regarded as less valuable than that of the Avenir Sustainability Project Team, since funding for programs under the Project came in large part from the redirection of the Traffic Committee or traffic engineering budget. Similarly, the confidence of team members in openly showing their influence over others was endorsed and rewarded by the wider practices of the organization, through its support for the work of this team.

The findings of a study focusing only on the information behaviour of participants would have been less rich in detail and nuance. The sharing of knowledge and expertise was the norm for this team and therefore unremarkable as they focused on solving a problem for a given street or park (Leith and Yerbury, 2015). There were few examples of exchange of documents, although the activities here categorized as presenting were clearly the sharing of knowledge. There were relatively few examples of team members suggesting that the contribution of another team member changed their knowledge base, although they clearly engaged with each other and the enthusiasm each had for the project and the new ways of working that it engendered were very clear. Influencing was rarely about using expertise to rebut the appropriate- ness of someone else's expertise. Here it was often about passing on a conversation where someone took the initiative to introduce the project and its principles; or what happened at a meeting; or sharing an insight into policies that favoured the work of the team either directly or indirectly. Resisting was not about withholding information, but about using expertise and 
insights in new ways of working to counter the norms of traditional work practices. Resisting, like influencing, was often apparent from reports of opportunistic meetings but was also developed tactically, through plans for approaches at formal meetings. In team meetings, these interchanges were almost always outside of the norms of sharing expertise. They might be dismissed as gossip or 'politicking', examples of the tensions that exist in any workplace, and therefore of little account. However, positioning these examples in the context of the wider organization, through the use of Kemmis and Grootenboer's (2008) theory of practice architectures, has shown that they are linked to an agenda for action in the Avenir Council at large and are examples of the skillful use of team members' knowledge and understanding of organizational practices.

\section{Conclusion}

The analysis of the examples of resisting the Traffic Committee and of influencing colleagues, management and community to adopt more sustainable approaches to Avenir Council operations uncovered how practice architectures may operate through the semantic, physical and social spaces. Such an analysis assists in gaining insight into how broader factors unfolding in an organizational site, may impact on, and mediate, practices such as knowledge sharing and organizational change. It also assists in highlighting the dynamic nature of these practices and how they, in turn, may 'loop back' to mediate these broader architectures of the wider organization.

The practice theoretical approach has been successful in highlighting the way in which knowledge sharing, organizational change and other practices are constituted and operate in the context of a local government organization, the Avenir Council. In particular, the approach offers the opportunity to develop a detailed and nuanced reading of the constituent activities of organizational practices, as well as the manner in which practices may interact and become enmeshed together through common activities. The team members' sayings, doings and relatings in the study uncover their high level of investment in knowledge sharing and organizational change, and how this investment is, in turn, impacted by the broader practice architectures present in the Avenir Council. This approach has facilitated findings which are more nuanced than would have been possible through more traditional conceptual approaches. In particular, it has extended research into information practices both by rein- forcing some previous practice-based studies and by con- firming that information practices are, like other practices, contextual, social, embodied and material in nature. It has also shown that knowledge sharing in organizational set- tings occurs beyond the exchange of expertise in a multi- disciplinary team. For librarians, and information and knowledge managers, this is significant, as it demonstrates that sharing knowledge of the organization, its policies and ways of working in successful project development and implementation may be just as important as sharing subject knowledge and expertise. For researchers, the approach opens the potential for new questions to be explored within the complexity of their context.

\section{Funding}

The author(s) disclosed receipt of the following financial support for the research, authorship, and/or publication of this article: This research is supported by an Australian Government Research Training Program (RTP) Scholarship.

\section{References}

Afrazeh A and Zarinozv I (2010) A conceptual framework for presenting and promoting human resource knowledge sharing in the supply chain as a social network. International Journal of Economics and Management 2(3/4): 227-245

Atkinson P (2011) Presenting to win: Mastering change and influence in uncertain times. Management Services 55(2): $44-47$.

Baesi C and Bejinaru R (2014) Issues of knowledge dynamics during organizational change. USV Annals of Economics and Public Administration 14(1/19): 147-153.

Battiliana J and Casciaro T (2012) Change agents, networks, and institutions: A contingency theory of organizational change. Academy of Management Journal 55(2): 381-398.

Battiliana J and Casciaro T (2013) Overcoming resistance to organizational change: Strong ties and affective co-optation. Management Science 59(4): 819-836.

Blake H and Lloyd S (2008) Influencing organizational change in the NHS: Lessons learned from workplace wellness initiatives in practice. Quality in Primary Care 1: 449-455.

Canning $\mathrm{J}$ and Found $\mathrm{P}$ (2015) The effect of resistance in organizational change programmes: A study of lean transformation. International Journal of Quality and Service Science 7(2/3): 274-295. 
Cudney E, Murra S, Sprague C, et al. (2015) Engaging health- care users through gamification in knowledge sharing of continuous improvement in healthcare. Procedia Manufacturing 3: 3416-3423.

Davis K and Boulet M (2016) Transformations? Skilled change agents influencing organizational sustainability culture. Australian Journal of Environmental Education 32(1): 109-123.

Feldman M and Pentland B (2003) Re-conceptualizing organizational routines as a source of flexibility and change. Administrative Science Quarterly 48: 94-118.

Frohmann B (1992) The power of images: A discourse analysis of the cognitive viewpoint. Journal of Documentation 48(4): $365-386$.

Georgalis J, Samaratunge R and Kimberley N (2015) Change process characteristics and resistance to organizational change: The role of employee perceptions of justice. Australian Journal of Management 40(1): 89-113.

Gillen M (2004) Promoting place: Elevating place-based dis- course and new approaches in local governance in NSW. Urban Policy and Research 22(2): 207-220.

Hepworth M, Grunewald P and Walton GL (2014) Research and practice: A critical reflection on approaches that underpin research into people's information behavior. Journal of Documentation 70(6):1039-1053.

Ingwersen P (1992) Information Retrieval Interaction. London: Taylor Graham.

Kawulich B (2005) Participant observation as a data collection method. Forum Qualitative Sozialforschung/Forum: Qualitative Social Research 6(2): article 43. Available at: http://nbn-resolving.de/urn:nbn:de:0114-fqs0502430.

Kemmis S (2009) Understanding professional practice: A synoptic framework. In: Green B(ed.) Understanding and Researching Professional Practice. Rotterdam: Sense,pp.19-38.

Kemmis S (2014) Reflections on how the theory of practice architectures is being used in the Nordic context. In: Ronnerman K and Salo P (eds) Lost in Practice: Transforming Nordic Educational Action Research. Rotterdam: Sense, pp. $205-217$.

Kemmis S and Grootenboer P (2008) Situating praxis in practice. In: Smith SK and Smith T (eds) Enabling Praxis: Challenges for Education. Amsterdam: Sense, pp. 37-62.

Kemmis S and Mutton R (2012) Education for sustainability (EfS): Practice and practice architectures. Environmental Education Research 18(2): 187-207.

Leith D and Yerbury H (2015) Organizational knowledge sharing, information literacy and sustainability: Two case studies from local government. In: Information literacy: Moving towards sustainability: Third European conference on information literacy (ECIL) (eds Kurbanoglu S, Boustany J, Špiranec S, et al.), Tallinn, Estonia, 19-22 October 2015, pp. 13-21. Cham: Springer.

Lloyd A (2012) Information literacy as a socially enacted practice: Sensitising themes for an emerging perspective of peoplein-practice. Journal of Documentation 68(6): 772-783.

Lozano R (2013) Are companies planning their organizational changes for corporate sustainability? An analysis of three case studies on resistance to change and their strategies to overcome it. Corporate Social Responsibility and Environmental Management 20: 275-295.

McCallum M, Vasconcelos W and Norman T (2008) Organizational change through influence. Autonomous Agents and Multi-Agent Systems 17: 157-189.

McGuinness S and Cronin H (2016) Examining the relationship between employee indicators of resistance to changes in job conditions and wider organizational change. Evidence- based HRM: A Global Forum for Empirical Scholarship 4(1): $30-48$.

Mahon K, Kemmis S, Francisco S, et al. (2017) Introduction: Practice theory and the theory of practice architectures. In: Francisco S, et al. (eds) Exploring Education and Professional Practice: Through the Lens of Practice Architectures. Singapore: Springer, pp. 1-30.

Mayfield M (2010) Tacit knowledge sharing: Techniques for putting a powerful tool in practice. Development and Learning in Organizations: An International Journal 24 (1): 24-26.

Navimipour N and Charband Y (2016) Knowledge sharing mechanisms and techniques in project teams: Literature review, classification and current trends. Computers in Human Behaviour 62: 730-742.

Nicolini D and Monteiro P (2017) The practice approach in organizational and management studies. In: Langley A and Tsoukas H (eds) The SAGE Handbook of Process Organization Studies. London: SAGE, pp. 110-126.

Patel D, Samara K and Patel S (2011) Review of knowledge sharing: Conceptual foundations for micro-level knowledge sharing and readiness-for-change related behaviours. In: ICT innovations 2010, CCIS 83 (eds Gusev M and Mitrevski P), Ohrid, Macedonia, 12-15 September 2010, pp. 11-26. Berlin: Springer.

Park S and Kim E-J (2015) Revisiting knowledge sharing from the organizational change perspective. European Journal of Training and Development 39(9): 769-797.

Pieterse J, Caniels M and Homan T (2012) Professional discourses and resistance to change. Journal of Organizational Change Management 25(6): 798-818.

Pilerot O (2013) A practice theoretical exploration of information sharing and trust in a dispersed community of design scholars. Information Research 18(4): paper 595. Available at http://InformationR.net/ir/18-4/paper595.html.

Pilerot O, Hammarfelt B and Moring C (2017) The many faces of practice theory in library and information studies. Information Research 22(1): CoLIS paper 1602. Available at: http://www.webcitation.org/6oJcNV0JJ. 
Price O (2009) Re-making jobs: Enacting and learning work practices. Vocations and Learning 2: 217-234.

Rechwitz A (2017) Practices and their affects. In: Hui A, Schatzki T and Shove E (eds) The Nexus of Practices: Connections, Constellations, Practitioners. London: Routledge, pp. 114-125.

Schatzki T (2002) The Site of the Social: A Philosophical Account of the Constitution of Social Life and Change. University Park, PA: Pennsylvania State University Press.

Schatzki T (2012) A primer on practices: Theory and research. In: Higgs J (eds) Practice-Based Education: Perspectives and Strategies. Rotterdam: Sense, pp. 13-26.

Tomaney J (2010) Place-Based Approaches to Regional Development: Global Trends and Australian Implications: A Report for the Australian Business Council. Melbourne: Monash University Press.

Untaru S (2002) Place-based planning for NSW local government. Australian Planner 39(2): 83-89.

Van Manen M (2014) Phenomenology of Practice: Meaning- Giving Methods in Phenomenological Research and Writing. Walnut Creek, CA: Left Coast Press.

Wilson TD (1997) Information behaviour: An interdisciplinary perspective. Information Processing \& Management 33(4): 551-572.

\section{Author biographies}

Dean Leith is a final year doctoral student in Information Studies at the University of Technology Sydney undertaking research into organizational knowledge sharing. He has over 20 years' senior management experience in media and digital publishing and specialist expertise in information management. His research interests include knowledge sharing, phenomenology and practice theoretical approaches to knowledge and information.

Hilary Yerbury is Adjunct professor in Information Studies at the University of Technology Sydney. Her background in European social and political cultures, information management, anthropology and development studies has given her a broad-based approach to the use of information in everyday decision making and in social change. 